\title{
Management of Diabetes in Africa: The Role of Traditional Medicines
}

\section{Mohamed Eddouks*}

Moulay Ismail University, BP 21, 52000, Errachidia, Morocco

\section{Diabetes Background}

Globally, diabetes is one of the most widespread diseases in existence that increased more than ten-fold in the last 40 years. Diabetes encompasses a group of diseases, in which the body's ability to convert glucose into energy is impaired, leading to a chronic condition. This metabolic disorder arises when the pancreatic beta cells are either unable to produce enough insulin, or the body cells do not respond to the released insulin. Even though diabetes itself is a big enough health problem, the side effects are equally ominous. For example, onethird of the new diabetic cases ended with diabetic nephropathy; $20 \%$ eventually die from cardiovascular diseases, and diabetes is the leading cause of amputation and blindness in elderly people [1-3].

\section{Management of Diabetes in Africa}

In Africa, there is a heavy dependence on Traditional medicines (TM) for the treatment of human diseases despite the availability of conventional pharmaceuticals. This is because the exorbitant cost and associated intolerable side-effects of most conventional pharmaceuticals prevent most people from being able to acquire them. According to the World Health Organization (WHO), about $80 \%$ of the world's population depends wholly or partly on plant-derived pharmaceuticals. Furthermore, about $25 \%$ of modern medicines are descended from plants first used traditionally. Metformin, a biguanide derived from two linked guanidine units; active constituents isolated from a medicinal plant Galega officinalis, is currently prescribed in the conventional medicine to treat diabetes. In the world today, there is a revolution in health care system, resulting in greater acceptance and trust in herbal medicine. Although some of these therapies may be helpful, others can be ineffective or toxic for human use. It is therefore important that the safety of any drug must be determined before its recommendation for human consumption [4].

\section{Traditional Medicines in Africa}

About $80 \%$ of the people in Africa use TM for the management of diabetes. The risk posed by TM is however not well documented. African plants used medicinally are widely assumed to be safe, but many are potentially toxic. The efficacy, safety and quality of raw medicinal plant materials and plant products depend on intrinsic or external factors. Inadvertent contamination during any of the production stages can affect the quality, safety and efficacy. Medicinal plants collected in the wild may be contaminated by other species. It is probable that adverse reactions to herbal products including potential herb-herb and herbdrug interactions are under-reported. Furthermore, majority of these products are self-prescribed and are used to treat, manage or control diabetic state in addition to the lack of understanding about the active ingredients of TM and their underlying therapeutic mechanisms [5].

It is for this reason that it seems very urgent to evaluate the safety of the use of TM in the management of diabetes, its efficacy, quality and standardization to protect this heritage and integrate it into the national health systems. In addition, the policies on the protection of indigenous or traditional knowledge are necessary.

\section{Regulatory Systems for Traditional Medicines}

In African countries, TM products are still not officially recognized under the law and there is no collected and standardized evidence on this type of health care. This is why the regulatory systems for TM should be widely adopted. The WHO is releasing a global plan to address a strategy able to provide a framework for policy to assist countries to regulate TM in order to make its use safer, more accessible to their populations and sustainable. The goal is to further develop TM based on research and innovation and to consider the inclusion of TM into the national health systems of these countries. The main objective of the WHO strategy is to develop national policies on the evaluation and regulation of TM, create a stronger evidence base on the safety, efficacy and quality of the TM products and practices and promote therapeutically sound use of TM by providers and consumers [6].

\section{Conclusion}

In Africa, an estimated $80 \%$ of people in the continent turn to traditional medicine as a source of primary care, including those with diabetes; however, the efficacy, safety and quality of raw medicinal plant are not well controlled and regulated. The strategy of WHO to encourage the African countries to integrate the TM in the management of chronic diseases represent a very precious tool to the management of diabetes in Africa under the optimal conditions of efficacy, safety and quality.

\section{References}

1. Rother KI (2007) Diabetes treatment--bridging the divide. N Engl J Med 356 1499-1501

2. Wild S, Roglic G, Greent A, Sicree R, King H (2004) Global prevalence of Diabetes: Estimates for the year 2000 and projections for 2030. Diabetes Care 27:1047-1053

3. Lee CM, Huxley RR, Lam TH, Martiniuk AL, Ueshema H, et al. (2007) Prevalence of diabetes mellitus and population attributable fractions for coronary heart disease and stroke mortality in the WHO South-East Asia and Western Pacific regions. Asia Pac J Clin Nutr 16: 187-192

4. Ernst E (2007) Prevalence of Use of Complementary/Alternative Medicine: A systematic review. Bull World Health Organ 78: 252-257

5. Jegede A, Oladosu P, Ameh S, Kolo I, Izebe K, et al. (2011) Status of management of diabetes mellitus by traditional medicine practitioners in Nigeria. Journal of Medicinal Plants Research 5: 6309-6315

6. World Health Organization (1996) WHO guidelines for the assessment of herbal medicine. WHO Expert Committee on specification for pharmaceutical preparation. Technical Report Series No. 863

*Corresponding author: Mohamed Eddouks, Moulay Ismail University, BP 21, 52000 Errachidia, Morocco, Tel: +212535573240; Email: mohamed.eddouks@laposte.net

Received September 24, 2012; Accepted September 25 2012; Published September 27, 2012

Citation: Eddouks M (2012) Management of Diabetes in Africa: The Role of Traditional Medicines. Pharmaceut Reg Affairs 1:e111. doi:10.4172/21677689.1000e111

Copyright: (c) 2012 Eddouks M. This is an open-access article distributed under the terms of the Creative Commons Attribution License, which permits unrestricted use, distribution, and reproduction in any medium, provided the original author and source are credited. 